\title{
DESENVOLVIMENTO DE PROTÓTIPO PARA AVALIAÇÃO DE HERBIGAÇÃO
}

\author{
Renato Adriane Alves Ruas ${ }^{1}$, Mauri Martins Teixeira ${ }^{2}$, Haroldo Carlos Fernandes ${ }^{2}$, Antônio Alberto da Silva ${ }^{3}$, \\ Rogério Faria Vieira ${ }^{4}$
}

\section{RESUMO}

Objetivou-se com este trabalho, construir e avaliar um protótipo a ser utilizado em ensaios de herbigação. O experimento foi realizado na casa de vegetação da EPAMIG, em Viçosa-MG. Determinou-se a uniformidade de distribuição volumétrica do sistema de aplicação, operando nas pressões de trabalho de 20, 40, 60, 80 e $100 \mathrm{kPa}$. Empregou-se o delineamento inteiramente casualizado, com quatro repetições. O delineamento experimental utilizado na avaliação da herbigação foi o inteiramente casualizado em esquema fatorial 4 x $3+3$ : quatro doses do fomesafem (60, 120, 180 e $\left.240 \mathrm{~g} \mathrm{ha}^{-1}\right)$, três estádios de desenvolvimento de Bidens pilosas (1, 7 e 14 DAE), e três testemunhas. Verificou-se o percentual de biomassa seca aos 35 DAE. Os dados foram submetidos à análise de variância, sendo as médias comparadas pelo teste de Newman Keuls, a $5 \%$ de probabilidade. Não houve diferença significativa para a uniformidade de distribuição volumétrica na parte central do sistema. O melhor controle da herbigação foi verificado com a dose de $240 \mathrm{~g} \mathrm{ha}^{-1}$ de fomesafem, independentemente da época de aplicação.

Palavras-chaves: Irrigação, herbigação, aplicação de agrotóxicos.

\section{ABSTRACT \\ DEVELOPMENT OF A PROTOTYPE FOR EVALUATING HERBIGATION}

This study was done to construct and evaluate a prototype to be used in trials herbigation. The experiment was carried out in a greenhouse of EPAMIG, in Viçosa, Minas Gerais. The uniformity of the volumetric distribution was determined by operating the application system at the working pressures of $20,40,60,80$, or $100 \mathrm{kPa}$. The herbigation experiment was laid in completely randomized design in 4 x $3+3$ factorial scheme. Fomesafem was applied at the rate of $60,120,180$ or $240 \mathrm{~g} \mathrm{ha}^{-1}$, after 1, 7 or 14 days of emergence of Bidens pilosas, with respective checks. The dry biomass was determined 35 days after emergence. Data were subjected to analysis of variance and the means were compared by Newman Keuls test $(\mathrm{p}=0.05)$. There was no significant difference between volumetric distribution

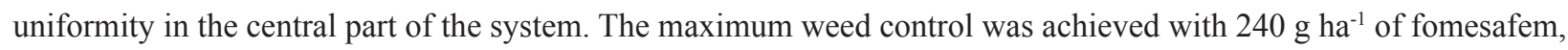
irrespective of the application time.

Keywords: Irrigation, herbigation, agrotoxics application.

\section{Recebido para publicação em 20/11/2009. Aprovado em 22/06/2010}

1- Prof. Dr. Adjunto I, Universidade Federal de Viçosa - Campus de Rio Paranaíba, renatoruas@ufv.br

2- Prof. Dr. Associado, Universidade Federal de Viçosa - Departamento de Engenharia Agrícola

3- Prof. Dr. Associado, Universidade Federal de Viçosa - Departamento de Fitotecnia

4- Pesquisador Dr. Empresa de Pesquisa Agropecuária de Minas Gerais/Embrapa, Viçosa-MG

\section{REVENG $112-117 \mathrm{p}$.}




\section{INTRODUÇÃO}

A aplicação de agrotóxicos via água de irrigação, ou quimirrigação pode ser realizada, empregando-se todos os métodos de irrigação: superfície, aspersão e localizada. Nas irrigações por superfície e localizada, é possível aplicar os agrotóxicos que têm o solo como alvo. Na irrigação por aspersão, a aplicação é feita em área total e os agrotóxicos podem ter como alvo tanto o solo quanto a parte aérea das plantas, ou ambos. Neste caso, geralmente são aplicados os herbicidas para o controle das plantas daninhas em condições de pós-emergência, os reguladores de crescimento e a maioria dos inseticidas e fungicidas (VIEIRA et al., 2003).

Ensaios com aplicação de agrotóxicos via água de irrigação, usando-se equipamentos simuladores, são importantes, pois, utilizam baixo volume de calda, diferentemente das quimigações convencionais, que aplicam elevados volumes, não sendo, portanto, adequadas para ensaios preliminares com agrotóxicos. Fontes et al. (1999) utilizaram um simulador de chuva para aplicação do fomesafen, em lâmina de água de 3,0 mm, na dosagem de $250 \mathrm{~g} \mathrm{ha}^{-1}$, visando ao controle de Raphanus raphanistrum, obtendo bons controles.

Segundo Vieira et al. (2003), o sucesso no uso de herbicidas aplicados via água de irrigação devese ao fato de eles possuírem pelo menos duas das seguintes características: baixa solubilidade em água; rápida absorção pelas folhas e absorção pelas raízes. Essas características são importantes, pelo fato de os agrotóxicos, quando aplicados via água de irrigação, apresentarem baixa concentração, em razão do elevado volume de água aplicado, e terem como alvo, na maioria das vezes, o solo, sendo retido pouco produto na folhagem das plantas. No entanto, herbicidas do grupo difeniléteres, como o fomesafem, têm a característica de serem rapidamente absorvidos pelos tecidos vegetais e, em menor intensidade, pelas raízes, podendo se locomover via apoplasto (DOWLER, 1987; ASHTON; MONACO, 1991; VIDAL, 1997).

De acordo com Hess (1987), após a aplicação de herbicida pelos métodos convencionais, a folha tratada, embora pareça completamente molhada, apresenta na verdade uma camada desuniforme de solução. Após a evaporação do solvente, essa camada dá origem a cristais sobre a superfície das folhas. Em razão de o movimento do herbicida através da cutícula da folha dar-se por difusão, a sua absorção pela planta só ocorre quando se encontra na forma de solução. Portanto, a formação de cristais sobre as folhas reduz a eficácia do herbicida e essa condição ocorre, com maior rapidez, quando o herbicida é aplicado pelos métodos convencionais. Logo, como na herbirrigação a cutícula permanece hidratada por mais tempo, é provável que isso favoreça a absorção do produto e, com isso, o agrotóxico propicie controle igual, ou melhor, que os métodos tradicionais de aplicação.

Uma das plantas daninhas de maior disseminação nas principais regiões agrícolas do País é a B. pilosa, constituindo-se em espécie responsável por sérios danos às culturas anuais e perenes. Além de competir pelos fatores de crescimento com a cultura, B. Pilosa também é hospedeira de patógenos. O aumento na densidade de plantas de B. pilosa pode provocar perdas no rendimento de grãos de soja de até $58 \%$ (RIZZARDI et al., 2003).

Objetivou-se com este trabalho, desenvolver um protótipo para avaliação da herbigação, visando à aplicação de fomesafen no controle de B. pilosa.

\section{MATERIAL E MÉTODOS}

O experimento foi realizado na casa de vegetação do Departamento de Fitotecnia da Universidade Federal de Viçosa. O protótipo para ensaios de herbigação foi constituído por depósito de 50 L (1), motobomba centrífuga de $1 \mathrm{cv}$ (2), filtro de tela de 200 mechas (4), registros (3), manômetro de glicerina (5), tubos de PVC de $32 \mathrm{~mm}$ de diâmetro e emissores (6 e 7). Os tubos de PVC foram arranjados em forma retangular, com 2,30 $\mathrm{m}$ de comprimento por $1,50 \mathrm{~m}$ de largura, posicionados a 1,0 m de altura do solo (Figura 1).

A aspersão foi realizada por seis emissores tipo difusor, modelo Micro-spray DEN: quatro de 1,2 $\mathrm{mm}$, com jato de ângulo de $90^{\circ}$, posicionados nos cantos, e dois de $1,0 \mathrm{~mm}$, com ângulo de jorro de $180^{\circ}$, posicionados no centro do simulador. Colocouse uma camada de brita na área de alcance das gotas aspergidas pelo sistema de aplicação, de modo a evitar empoçamento de água; utilizou-se também um piso de madeira, que cobria uma área de dois metros quadrados, para apoio e marcação da posição dos vasos no momento das aplicações. A parte central da área, cerca de um metro quadrado, é destinada ao posicionamento dos alvos a serem aspergidos. 
Foram distribuídos 84 coletores da marca Fabrimar, próprios para a determinação da uniformidade de distribuição de água dos sistemas de irrigação por aspersão, espaçados 0,15 m entre si, posicionados sobre o piso do sistema de aplicação. Após o funcionamento do sistema, por dez minutos, coletou-se e mediu-se o líquido dos coletores. A área do ensaio foi cercada por uma lona plástica, para que a água não fosse aplicada além da área experimental. A temperatura do ambiente durante a realização do ensaio variou entre 25 e $29^{\circ} \mathrm{C}$ e a umidade relativa do ar, entre 70 e $76 \%$.

$\mathrm{O}$ método utilizado para avaliação da uniformidade de distribuição volumétrica foi o Coeficiente de Uniformidade de Christiansen (CUC) (Equação 1):

$$
C U C=100\left(1-\frac{\sum_{I=1}^{n}\left|X_{I}-\bar{X}\right|}{n \bar{X}}\right)
$$

em que,

$$
\begin{aligned}
& \text { CUC }= \begin{array}{l}
\text { Coeficiente de Uniformidade de } \\
\text { Christiansen, em } \% ;
\end{array} \\
& X_{i}=\begin{array}{l}
\text { precipitação obtida em cada coletor, } \\
\text { em } \mathrm{mL} ;
\end{array} \\
& \overline{\mathrm{X}}=\text { médias das precipitações, em } \mathrm{mL} ; \mathrm{e} \\
& n=\text { número de coletores. }
\end{aligned}
$$

Foram medidas, também, a vazão e a lâmina de água aplicada durante o tempo utilizado para a determinação da uniformidade de distribuição volumétrica do sistema, em cinco diferentes pressões de trabalho $(20,40,60,80$ e 100 $\mathrm{kPa}$ ). Para isso, empregou-se o delineamento inteiramente casualizado, com quatro repetições. Os dados foram submetidos à análise de variância e as médias comparadas utilizando-se o teste de Newman Keuls, a 5\% de probabilidade.

Após a verificação de suas características técnicas, o protótipo foi utilizado para avaliação do herbicida fomesafen, em três estádios de crescimento de plantas de B. pilosa: 1, 7 e 14 dias após a emergência (DAE), com alturas de $0,72,2,25$ e $3,87 \mathrm{~cm}$, respectivamente. As plantas foram cultivadas em vasos de polietileno de $4 \mathrm{~L}$, contendo inicialmente 50 plantas cada um. Foram aplicadas quatro doses do fomesafem $(60,120,180$ e $\left.240 \mathrm{~g} \mathrm{ha}^{-1}\right)$. A lâmina média de água aplicada nas herbirrigações foi de $4,72 \mathrm{~mm}$, sendo este valor considerado adequado para aplicação de produtos que visam à folhagem das plantas. Estes produtos devem ser aplicados na menor lâmina possível e, em geral, com os pivôs centrais comercializados no Brasil, a menor lâmina de água possível de ser obtida fica entre 4 e 8 mm (VIEIRA; SILVA, 1998).

A avaliação dos tratamentos foi feita aos 35 dias após a emergência das plantas, determinando-se o acúmulo de biomassa seca pelas plantas daninhas, para os tratamentos realizados a um, sete e 14 DAE, respectivamente. Para esta avaliação, fez-se o corte das plantas rente ao solo, secando-as em seguida em estufa, a $70 \pm 1{ }^{\circ} \mathrm{C}$, durante 72 horas, para posterior determinação da biomassa seca em balança de precisão.

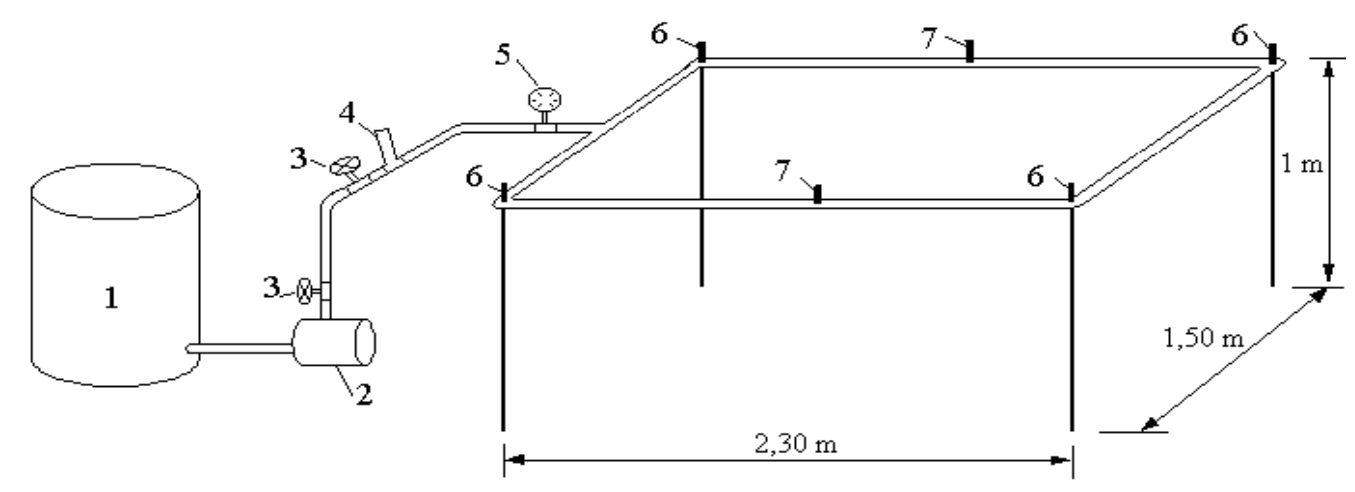

Figura 1. Protótipo desenvolvido para execução de ensaios de herbigação.

\section{REVENG \\ 112-117 p.}

ENGENHARIA NA AGRICULTURA, VIÇOSA - MG, V.19 N.2, MARÇO / ABRIL 2011 
O delineamento experimental utilizado na avaliação da herbirrigação foi $\mathrm{o}$ inteiramente casualizado, em esquema fatorial $4 \times 3+3$, sendo quatro doses do fomesafem $(60,120,180 \mathrm{e}$ $\left.240 \mathrm{~g} \mathrm{ha}^{-1}\right)$, três estádios de desenvolvimento das plantas daninhas (1,7 e 14 DAE), e três testemunhas (uma para cada estádio de desenvolvimento das plantas daninhas), que não receberam herbicida. Os dados foram submetidos à análise de variância, sendo as médias dos tratamentos comparadas pelo teste de Newman Keuls, a $5 \%$ de probabilidade. A comparação de cada tratamento com herbicida e as respectivas testemunhas, em cada estádio, foi feita utilizando-se o teste de Dunnett, a $5 \%$ de probabilidade. As análises estatísticas foram realizadas, empregando-se o programa estatístico Saeg 8.0.

\section{RESULTADOS E DISCUSSÃO}

Observa-se que somente na pressão de $100 \mathrm{kPa}$ o protótipo construído para realização de ensaios de herbigação apresentou CUC abaixo de $80 \%$, valor mínimo aceitável para os sistemas de irrigação por aspersão (Quadro 1). Valores de CUC abaixo de $80 \%$, geralmente, resultam da ação de vento forte, da pressão de trabalho inadequada para o sistema, do desgaste do equipamento ou da interação entre todos esses fatores (BERNARDO, 1995). Para as demais pressões de trabalho, os valores de CUC ficaram acima de $80 \%$.

$\mathrm{Na}$ área central do sistema de aplicação, verificou-se elevada uniformidade de distribuição, com CUCs acima de $94 \%$. Isso ocorreu porque, nessa área, a sobreposição dos jatos foi maior, principalmente nas menores pressões. Isso demonstraquea aplicação de umprodutoquímicovia água de irrigação, nessas condições, possivelmente resultaria numa distribuição do ingrediente ativo bastante satisfatória, pois, segundo Cruz (1997), a uniformidade de distribuição do agrotóxico aplicado via água de irrigação, normalmente, é proporcional à uniformidade de distribuição da água.

As lâminas de água aplicadas utilizando o sistema, durante a determinação do CUC, situaramse entre 6,25 e 17,96 mm (Quadro 1), sendo semelhantes àquelas usadas pelos agricultores na herbirrigação, quando utilizam pivô central.

Quanto ao acúmulo de biomassa seca de B. pilosa, a análise de variância mostrou que a interação entre doses e estádios foi significativa a 5 $\%$ de probabilidade, pelo teste $\mathrm{F}$.

A aplicação do fomesafen proporcionou melhor controle quando realizada aos 7 DAE, na dosagem de $240 \mathrm{~g} \mathrm{ha}^{-1}$ (0,032 g) (Quadro 2). Isso pode ser justificado pela maior absorção do herbicida, principalmente por causa da existência de maior área foliar e da maior susceptibilidade das plantas nesse estádio, em relação aos outros estádios em que o herbicida foi aplicado. Aos 7 DAE, as plantas já haviam emitido a folha definitiva, razão pela qual houve maior retenção do herbicida pela parte aérea. Além disso, supõese que houve absorção radicular, pois, segundo Procópio et al. (2002), neste estádio, a espécie B. pilosa apresenta maior desenvolvimento do sistema radicular em relação à parte aérea, o que pode ter favorecido a absorção do herbicida pelas raízes.

Quadro 1. Vazão, lâmina de água aplicada e Coeficiente de Uniformidade de Christiansen obtidos em operação do sistema de aplicação sob diferentes pressões

\begin{tabular}{|c|c|c|c|c|}
\hline \multirow{2}{*}{$\begin{array}{l}\text { Pressão } \\
(\mathrm{kPa})\end{array}$} & \multirow{2}{*}{$\begin{array}{l}\text { Vazão } \\
\left(\mathrm{m}^{3} \mathrm{~h}^{-1}\right)\end{array}$} & \multirow{2}{*}{$\begin{array}{l}\text { Lâmina de } \\
\text { água } \\
\text { (mm) }\end{array}$} & \multicolumn{2}{|c|}{ Coeficiente de Uniformidade de Christiansen (\%) } \\
\hline & & & Área total & Área central \\
\hline 20 & 0,22 & 6,25 & $92,11 \mathrm{a}^{1}$ & $94,97 \mathrm{a}$ \\
\hline 40 & 0,26 & 9,44 & $88,07 \mathrm{~b}$ & 95,91 a \\
\hline 60 & 0,28 & 11,82 & $84,54 \mathrm{c}$ & 96,79 a \\
\hline 80 & 0,30 & 13,58 & $82,57 \mathrm{~cd}$ & $95,73 \mathrm{a}$ \\
\hline 100 & 0,32 & 17,96 & $79,91 \mathrm{~d}$ & $95,10 \mathrm{a}$ \\
\hline
\end{tabular}

${ }^{1}$ Médias seguidas pela mesma letra, nas colunas, não diferem significativamente entre si pelo teste de Newman Keuls $(\mathrm{P}>0,05)$. 
De acordo com Vieira et al. (2003), para se obter controle eficaz das plantas daninhas por herbicidas aplicados em pós-emergência, é muito importante a retenção foliar. $\mathrm{Na}$ pulverização convencional, os herbicidas geralmente são distribuídos em média com 100-200 L ha-1 de água, o que minimiza o escorrimento da calda que atinge as folhas das plantas. No entanto, na herbirrigação, o elevado volume de água utilizado faz com que grande parte do produto tenha como destino o solo, por causa do escorrimento da calda que não fica retida nas folhas. Neste caso, o produto deveria ser absorvido pelas raízes e translocado pelas plantas até seu sítio de ação, para se ter bom controle, o que pode ser diferenciado para cada espécie.

Somente as dosagens de 60 e $120 \mathrm{~g} \mathrm{ha}^{-1}$, aplicadas aos 14 DAE, não proporcionaram diferença estatística em relação às testemunhas; nas demais dosagens, os valores de biomassa seca, obtidos nas parcelas tratadas, foram inferiores aos das testemunhas (Quadro 3).

As aplicações das dosagens realizadas nos estádios 1 e 7 DAE resultaram em menorquantidade de biomassa seca de B. pilosa, à medida que se aumentaram as dosagens. Comparativamente aos demais estádios, o acréscimo das dosagens de fomesafen, quando as plantas estavam com 14 DAE, resultou em pequena diminuição no acúmulo de biomassa seca, indicando que nesta época de aplicação não é a mais adequada para o controle de B. pilosa.

\section{CONCLUSÃO}

- A uniformidade de distribuição volumétrica no protótipo de ensaios de herbigação foi variável com a pressão de trabalho;

Quadro 2. Biomassa seca de Bidens pilosa, em gramas/vaso, tratadas em diferentes estádios com fomesafem, em quatro dosagens via herbirrigação e colhidas aos 35 dias após a emergência (DAE)

\begin{tabular}{cccc}
\hline Doses & \multicolumn{3}{c}{ Estádios de aplicação do fomesafen } \\
\cline { 2 - 4 }$\left(\mathrm{g} \mathrm{ha}^{-1}\right)$ & $1 \mathrm{DAE}$ & $7 \mathrm{DAE}$ & $14 \mathrm{DAE}$ \\
\hline 60 & $1,170 \mathrm{a}^{1}$ & $1,171 \mathrm{a}$ & $1,263 \mathrm{a}$ \\
120 & $1,089 \mathrm{a}$ & $0,895 \mathrm{a}$ & $1,241 \mathrm{~b}$ \\
180 & $0,339 \mathrm{a}$ & $0,139 \mathrm{~b}$ & $0,767 \mathrm{c}$ \\
240 & $0,211 \mathrm{a}$ & $0,032 \mathrm{~b}$ & $0,501 \mathrm{a}$ \\
\hline
\end{tabular}

${ }^{1}$ Em cada dose, as médias seguidas pela mesma letra comparadas nas linhas, não diferem entre si a $5 \%$ de probabilidade, pelo teste de Newman Keuls.

Quadro 3. Biomassa seca de Bidens pilosa, em gramas/vaso, tratadas em diferentes estádios com fomesafem, em quatro dosagens via herbirrigação e colhidas aos 35 dias após a emergência (DAE), comparadas com as respectivas testemunhas

\begin{tabular}{cccc}
\hline \multirow{2}{*}{$\begin{array}{c}\text { Doses } \\
\left(\mathrm{g} \mathrm{ha}^{-1}\right)\end{array}$} & \multicolumn{3}{c}{ Estádios de aplicação do fomesafen } \\
\cline { 2 - 4 } & $1 \mathrm{DAE}$ & $7 \mathrm{DAE}$ & 14 DAE \\
\hline 60 & $1,170^{* 1}$ & $1,171^{*}$ & 1,263 \\
120 & $1,089^{*}$ & $0,895 *$ & 1,241 \\
180 & $0,339^{*}$ & $0,139 *$ & $0,767 *$ \\
240 & $0,219^{*}$ & $0,032 *$ & $0,501 *$ \\
\hline Testemunha & 1,777 & 1,498 & 1,422 \\
\hline
\end{tabular}

${ }^{1}$ Em cada estádio de aplicação, as médias seguidas de asterisco diferem da testemunha a $5 \%$ de probabilidade, pelo teste de Dunnett.

\section{REVENG


- O protótipo de ensaios de herbigação proporcionou maior uniformidade de distribuição de água na sua área central; e

- A dose de $240 \mathrm{~g} \mathrm{ha}^{-1}$ de fomesafem, aplicada utilizando-se o protótipo de ensaios de herbigação, proporcionou melhor controle de $B$. pilosa, independentemente da época de aplicação.

\section{REFERÊNCIAS BIBLIOGRÁFICAS}

ASHTON, F.M.; MONACO, T.J. Weed Science: principles \& practices. 3 ed. New York: John Wiley \& Sons, 1991, 466p.

BERNARDO, S. Manual de Irrigação. 6 ed. Viçosa: Imprensa Universitária, UFV ,1995. 657p.

CRUZ, C.O. Distribuição horizontal do inseticida chlororpyrifos aplicado via pivô central em cultura de milho (Zea mays L.) e sua retenção no dossel das plantas. 1997. 54 f. Dissertação (Mestrado em Engenharia Agrícola) - Universidade Federal de Lavras, Lavras. 1997.

DOWLER, C.C. Efficacy of some recently developed herbicides applied through irrigation. In: SOUTHERN WEED SCIENCE SOCIETY, 1987, Orlando, Florida. Proceedings...: SWSS Champaign, IL, v.12, n.4 p.372-374, 1987.

FONTES, J.R.A.; SILVA, A A.; LEITE, J.A.O.; VIEIRA, R.F.; RAMOS, M.M. Aplicação de herbicidas em pós-emergência via água de irrigação na cultura do feijão. In: REUNIÃO NACIONAL DE
PESQUISA DE FEIJÃO, 1999.Salvador, Anais... Salvador: v.1, n. 6, p.459-461, 1999.

HESS, F.D. Relationship of plant morphology to herbicide application and absorption. In: McWHORTER, C.G. \& GEBHARDT, M. R. (eds.). Methods of applying herbicides. WSSA, Champaign, IL, v.9, n.3,. p.19-35, 1987.

VIDAL, R.A. Herbicidas: mecanismo de ação e resistência de plantas. Porto Alegre: R.A. Vidal. 165 p. 1997.

VIEIRA, R.F.; SILVA, A.A. da; RAMOS, M.M. Aplicação de herbicidas em condições de pósemergência via água de irrigação por aspersão Revisão. Revista Plantas Daninhas, Viçosa, v.21, n. 3, p.495-506, 2003.

VIEIRA, R.F.; SILVA, A.A. da. Aplicação de defensivos via água de irrigação por aspersão. In: VIEIRA, C., PAULA JÚNIOR, T.J. de, BORÉM, A. Feijão. Aspectos gerais e cultura no Estado de Minas. Viçosa: Editora UFV. p. 267-323. 1998.

PROCÓPIO, S.O; SANTOS, J.B; SILVA, A.A; Análise do crescimento e eficiência no uso da água pelas culturas de soja e do feijão e por plantas daninhas. Acta Scientiarum. Maringá, v.24, n.5, p.1345-1351, 2002.

RIZZARDI, M.A.; FLECK, N.G.; MUNDSTOCK, C.M. Perdas de rendimento de grãos de soja causadas por interferência de picão-preto e guanxuma. Ciência Rural, Santa Maria RS, v.33, n.4, p.621-627, 2003. 